\title{
Fabrication of Porous Magnesium Alloys by Pulse Electric Current Sintering Process Using Machined Chips
}

\author{
Hayato Okumura, Kohji Watanabe*, Shigeharu Kamado and Yo Kojima \\ Department of Mechanical Engineering, Nagaoka University of Technology, Nagaoka 940-2188, Japan
}

Magnesium based porous materials are made by Pulse-Electric-Current-Sintering (PECS) method using cut chips. Commercial ingots of AZ91D and AM60B alloys and extruded AZ31 alloy were selected as raw materials in order to change the amount of eutectic compounds and the range of semi-solid temperatures. Porous materials of various plateau stresses could be made by PECS process depending on pore ratio, alloy composition and sintering temperature. In well-joined parts of porous samples of AZ91D and AM60B alloy, Mg-Al system compounds crystallize, while the aluminum content at the joined part of AZ31 porous sample is concentrated. This means that the non-equilibrium solidified $\mathrm{Mg}-\mathrm{Al}$ compound is preferentially remelted by rapid heating during PECS. Thus the difference in the microstructures of the joined parts is caused by the different aluminum contents of the alloys. The condition for making the well-joined porous materials using PECS process is to use alloys that have large amount of low melting compounds and large semi-solid temperature range. The plateau stresses of the porous materials investigated in this study are in the range from 1.3 to $37.3 \mathrm{MPa}$ and pore ratio is the most important factor affecting plateau stress.

(Received October 23, 2002; Accepted November 26, 2002)

Keywords: magnesium alloy, pulse electric current sintering, plateau stress, semi-solid temperature, impact compressive property

\section{Introduction}

Recently, negative changes in the earth's environment due to high emission of $\mathrm{CO}_{2}$ and energy conservation measures have made it important to reduce the weight of transport vehicles in order to improve fuel efficiency and curtail $\mathrm{CO}_{2}$ gas emission. Therefore, aluminum and magnesium alloys have been used as substitution for steel. More attention is paid to magnesium alloys, which are lighter than aluminum alloys. However, magnesium alloys do not have enough high temperature strength and good ductility. Therefore, numerous studies are being carried out on new alloy development ${ }^{1-3)}$ and improvement of wrought alloys. ${ }^{4-6)}$ Presently, aluminum alloys are used in many parts of the vehicle, but magnesium alloys are only used in a few parts. However, suitable magnesium alloys have been developed for diecasting of lightweight automotive power train parts that will help to broaden the application of magnesium alloys. ${ }^{7)}$ In term of vehicle development and evolution up to date, vehicle collision is now a big danger because the vehicle body has become thin due to lightweight measures to improve vehicle performance. Therefore, attention is being paid to impact absorbing materials from the viewpoint of safety in case there is vehicle collision. Presently, aluminum extruded products are used as impact absorbing materials in vehicles. The aluminum products absorb impact energy continuously when they fail in compression during head-on collision. However, aluminum extruded products are too strong, so their impact energy absorbing ability can only protect the vehicle itself from excess damage, but the impact is still transmitted to the occupants, resulting in fatalities during head-on collision.

Therefore, porous materials that can absorb various impacts by changing the amount and size of pores must be developed. The application of porous materials are expected to include weight reduction of vehicles, filters, vibration/

*Bachelor Student, Nagaoka University of Technology. Present address: HITEC. Co., Ltd. sound proof materials, buffer materials and substitute bone for transplantation and so on, because they are lightweight materials and they have high energy absorbing ability as well as transformation and insulation abilities. ${ }^{8)}$ Porous materials are made by various methods. The most popular methods are casting, plating, powder metallurgy and sputter deposition methods. The casting method consists of gas injection, lost core and investment (lost wax) methods. ${ }^{9)}$ Recently, porous materials of lotus type have been developed utilizing metalgas system reaction. ${ }^{10)}$ The characteristic feature of this type of porous material is that pore direction can be controlled. However, production of porous materials using these common methods usually involves many strenuous processes.

Aluminum cellular materials have been extensively developed and investigated using those preparation methods. ${ }^{11-13)}$ Among all porous materials, the commercial closed-cell foam, ALPORAS ${ }^{14)}$ is the most popular and it is made by Shinko Wire process, which is a kind of gas injection method. However, magnesium cellular materials are being studied vigorously, because magnesium has a lower density compared to aluminum. ${ }^{15-17)}$

Therefore, in this study, an attempt is made to produce magnesium porous materials by Pulse-Electric-Current-Sintering (PECS) method using magnesium chips, because this method is simple compared to other methods. PECS method is carried out by rapid sintering in a low voltage/high current situation utilizing direct pulse current under a single axis pressurization. The actual sintering phenomenon that occurs during PECS is still subject to various opinions. However, in general, PECS is a rapid sintering process during which localized melting and vaporization occur by remarkable heat generation and discharge around the joined part. ${ }^{18)}$

On the other hand, magnesium has good machining characteristics, but the chips are dangerous due to easy burning. Consequently, there is always a problem of chips disposal during machining of magnesium and its alloys. Thus the production of porous materials using magnesium chips could be an effective way of utilizing chips as one of 
Table 1 Chemical composition of each alloy (mass\%).

\begin{tabular}{ccccccccc}
\hline Alloy & $\mathrm{Al}$ & $\mathrm{Zn}$ & $\mathrm{Mn}$ & $\mathrm{Fe}$ & $\mathrm{Cu}$ & $\mathrm{Ni}$ & $\mathrm{Si}$ & $\mathrm{Mg}$ \\
\hline AZ31 & 3.0 & 1.0 & 0.4 & 0.003 & 0.05 & 0.005 & 0.01 & Bal. \\
AM60B & 5.7 & 0.007 & - & 0.003 & $<0.001$ & - & 0.02 & Bal. \\
AZ91D & 9.1 & 0.7 & 0.23 & 0.003 & 0.002 & 0.001 & 0.03 & Bal. \\
\hline
\end{tabular}

recycling method. Magnesium porous materials are easily made by PECS method compared to other methods. Sintering conditions are established by changing the sintering temperature, pore ratio and alloy composition. Then the range of plateau stresses that result from compression tests of the magnesium based porous materials made by PECS method are investigated.

\section{Experimental Procedure}

In this study, commercial ingots of AZ91D and AM60B alloys and extruded AZ31 alloy, which contain various amounts of aluminum were used. The reason for selecting these alloys is because the amount of eutectic compounds change with aluminum content. Table 1 shows the chemical compositions of the investigated alloys. The chips of the alloys were cut using a lathe machine, and then the chips were used as raw materials for PECS. The mold and punch used were made of graphite. Sintering was carried out under Ar gas atmosphere of $0.14 \mathrm{MPa}$. The specimens were heated for $10 \mathrm{~min}$ from room temperature to the sintering temperature and held at that temperature for another $10 \mathrm{~min}$. Initially, PECS was carried out at different sintering temperatures of 500, 530, 550, 575 and $600^{\circ} \mathrm{C}$ and a target density of $0.5 \mathrm{Mg} / \mathrm{m}^{3}$. Furthermore, in order to investigate the effects of pore ratio on the properties of the porous materials, different target densities of $1.0,0.75,0.5$ and $0.4 \mathrm{Mg} / \mathrm{m}^{3}$ corresponding to $78,74,65$ and $50 \%$ pore ratios, respectively, were processed at $575^{\circ} \mathrm{C}$ using AZ91D alloy chips. Subsequently, all of the alloys were subjected to PECS at the most suitable sintering temperature and target density of $0.5 \mathrm{Mg} / \mathrm{m}^{3}$ in order to investigate the influence of alloy compositions on the properties of the porous materials.

The microstructures of obtained specimens were observed using both optical and scanning electron microscopes and particular attention was paid to the joined part of the chips. The specimens were also analyzed using X-ray diffractometer and EPMA. Compressive test was carried out using a high speed material test system with special load sensing block made by Saginomiya Seisakusho, INC. The compression characteristics of the porous materials were also evaluated by carrying out further compressive tests at strain rates of $5.7 \times 10^{-3}, 1.4$ and $7.1 \times 10^{2} \mathrm{~s}^{-1}$.

\section{Results and Discussion}

\subsection{Microstructure}

The chips used in this study were cut using a lathe machine at a rotation speed of $1000 \mathrm{rpm}$, tool speed of $1.3 \mathrm{~mm} / \mathrm{rev}$ and a feed of $0.05 \mathrm{~mm}$. Figure 1 shows the shape and appearance, as well as a cross section of the chips of the investigated alloys. The chips of all alloys have a curly shape as shown in left figures and a saw teeth appearance peculiar to magne-
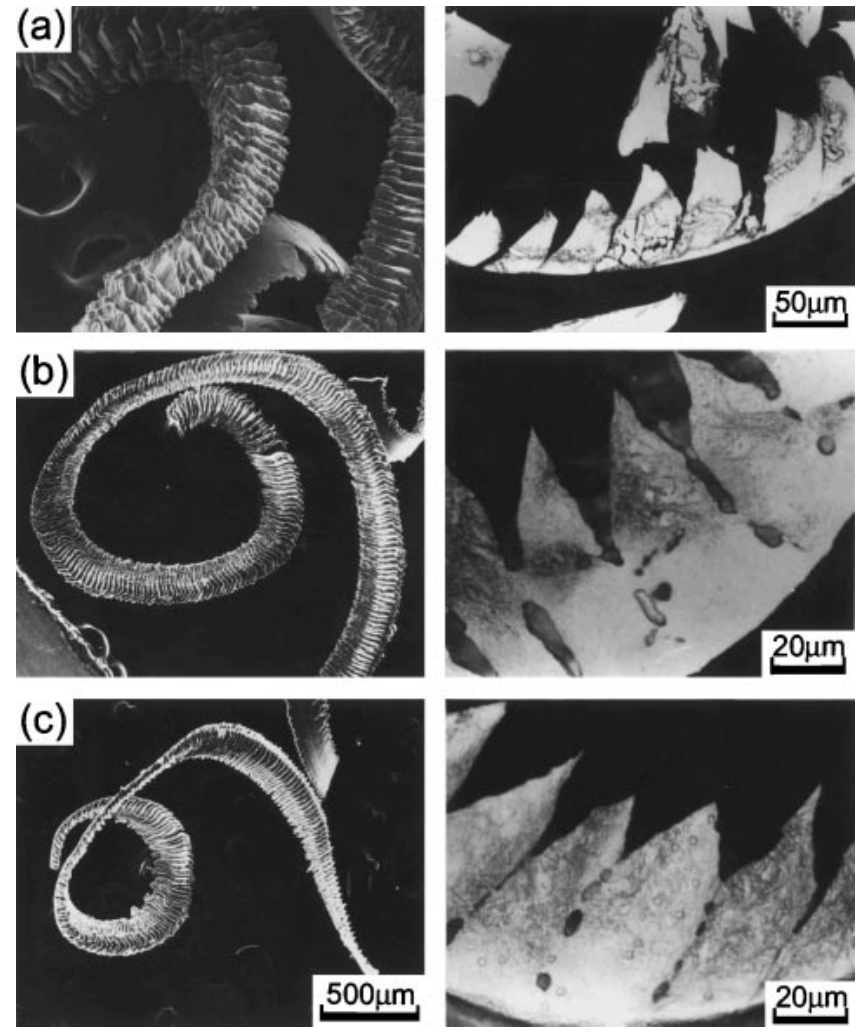

Fig. 1 Chip appearance and cross section of the chips of (a) AZ91D, (b) AM60B and (c) AZ31 alloys.

sium alloys. The thickness of the chips is about $80 \mu \mathrm{m}$.

Figure 2 shows the changes in microstructure of joined parts of specimens of AZ91D alloy processed at different sintering temperatures and pore ratios of (a) $550^{\circ} \mathrm{C}, 74 \%$, (b) $575^{\circ} \mathrm{C}, 74 \%$ and (c) $575^{\circ} \mathrm{C}, 50 \%$. When the pore ratio is $74 \%$, as shown in (a) and (b), the sintering temperature of $550^{\circ} \mathrm{C}$ is not sufficient because the chips still maintain the initial saw teeth appearance and the joined part appears weak. Generally, the chip appearance changes from the initial saw teeth to round with increasing sintering temperature. At the sintering temperature of $575^{\circ} \mathrm{C}$, the shape of the chips is round and the joined part appears adequate. Therefore, $575^{\circ} \mathrm{C}$ can be assumed to be a sufficient sintering temperature for AZ91D alloy and then the effect of pore ratio was evaluated at that temperature. Figure 2(c) shows the effect of increasing the amount of chips, that is, decreasing pore ratio. At a low pore ratio of $50 \%$, only a few joined parts are melted during PECS, because the intensity of pulse current passing through the chips contact point is low. In the case of a high pore ratio of $74 \%$ (small amount of chip), the pulse current passing through the chips contact point is high and it is spent in melting of the chip itself. Therefore, this is thought to be the reason why the chip appearance becomes round with increasing pore ratio. Details of the effect of changing the pore ratio and the sintering temperature on the microstructure of AZ91D porous materials have been described in an earlier paper. ${ }^{19)}$

Figure 3 shows the microstructures of joined parts of the investigated alloys. Each alloy was sintered at a suitable temperature and the density of the porous materials was constant at $0.5 \mathrm{Mg} / \mathrm{m}^{3}$. The evaluation of the joined parts is 
(a)Sintering Temperature: $550^{\circ} \mathrm{C}$, Density: $0.46 \mathrm{Mg} / \mathrm{m}^{3}$, Pore ratio: $74 \%$
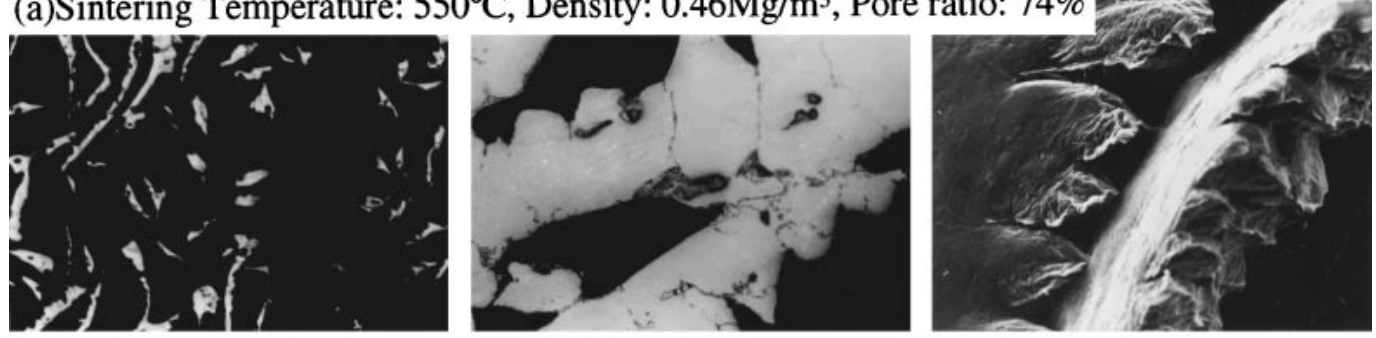

(b)Sintering Temperature: $575^{\circ} \mathrm{C}$, Density: $0.46 \mathrm{Mg} / \mathrm{m}^{3}$, Pore ratio: $74 \%$
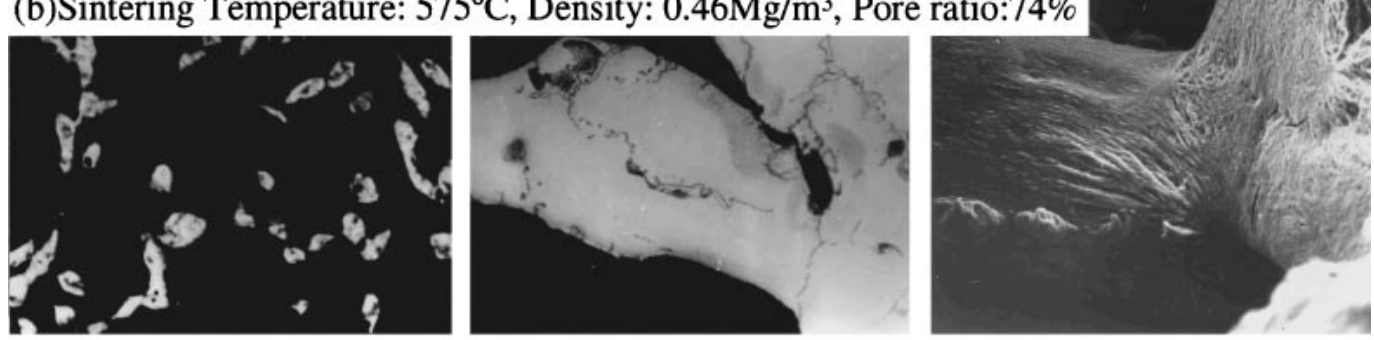

(c)Sintering Temperature: $575^{\circ} \mathrm{C}$, Density: $0.91 \mathrm{Mg} / \mathrm{m}^{3}$, Pore ratio: $50 \%$
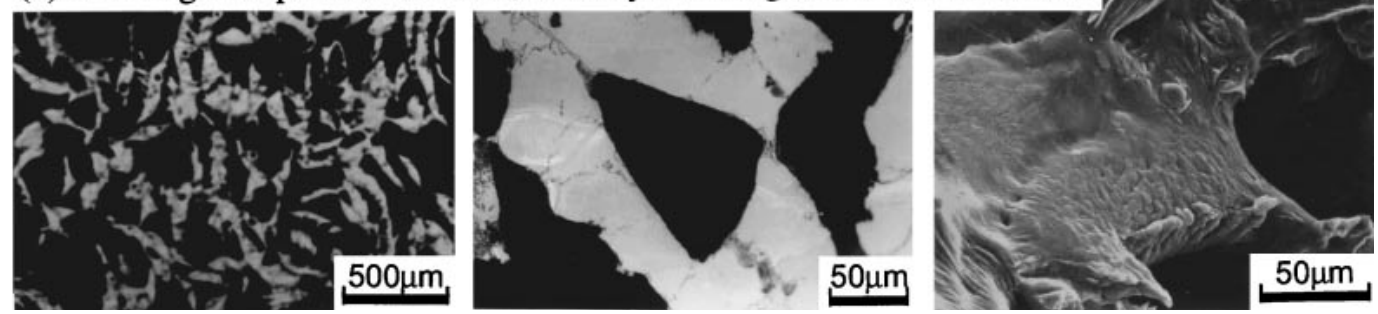

Fig. 2 Changes in microstructures of joined parts of specimens of AZ91D alloy processed at different sintering temperature and pore ratio of (a) $550^{\circ} \mathrm{C}, 74 \%$, (b) $575^{\circ} \mathrm{C}, 74 \%$, (c) $575^{\circ} \mathrm{C}, 50 \%$.

(a)AZ91D, Sintered temperature:575 ${ }^{\circ} \mathrm{C}$

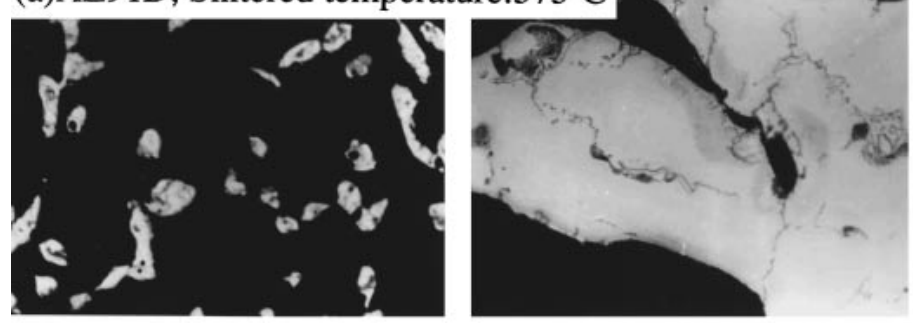

(b)AM60B, Sintered temperatus

(c)AZ31, Sintered temperature: $665^{\circ} \mathrm{C}$

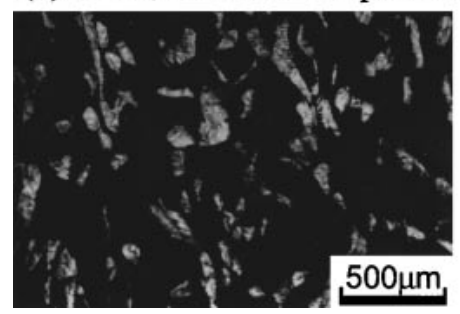

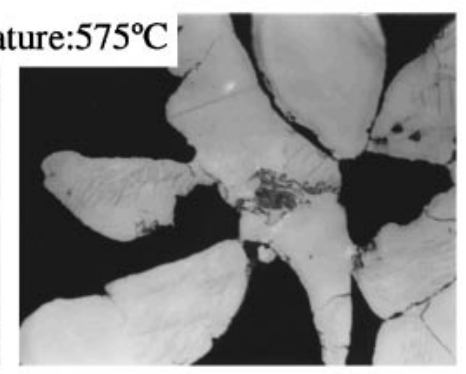
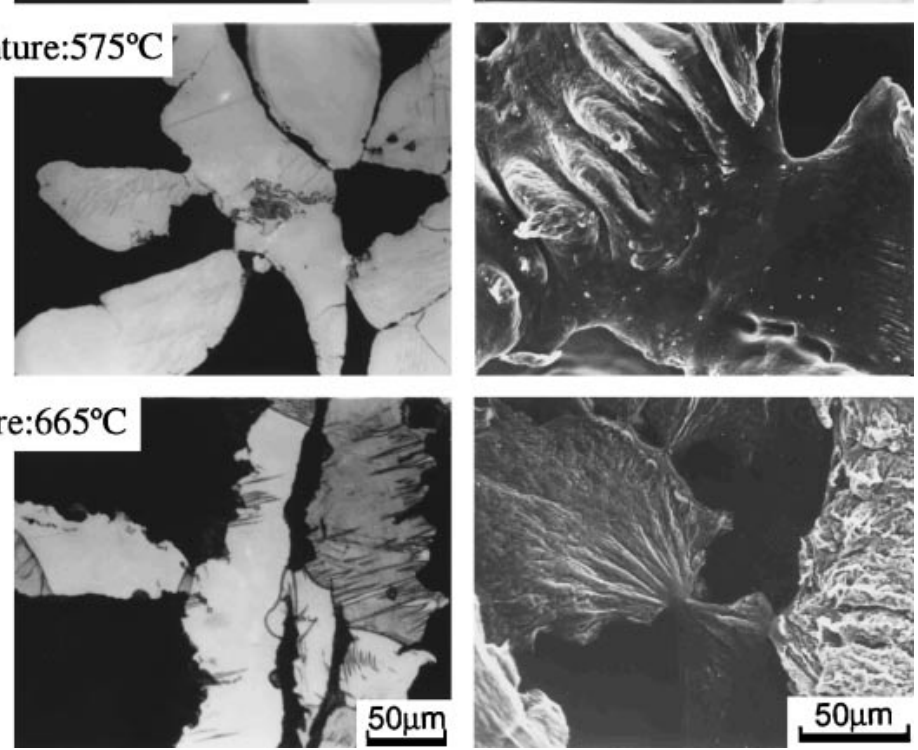
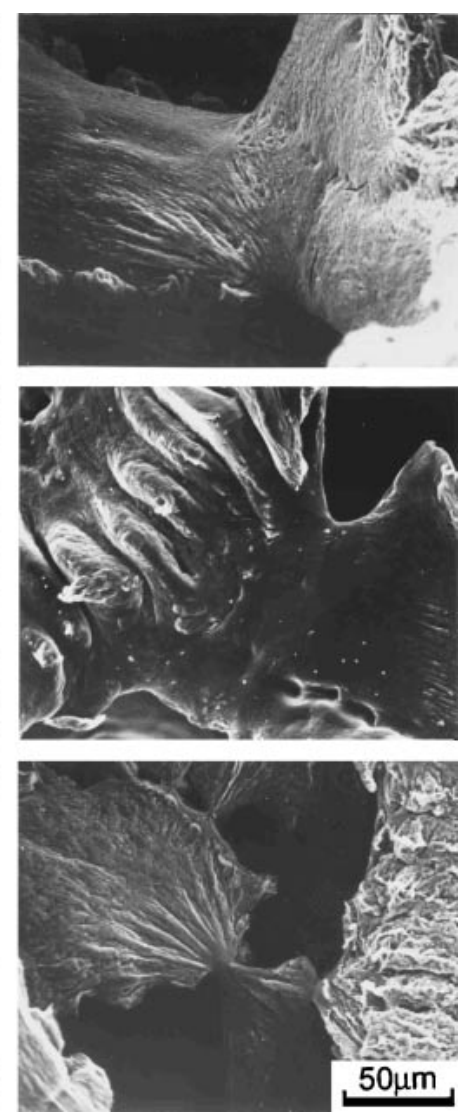

Fig. 3 Microstructures of joined parts of (a) AZ91D, (b) AM60B and (c) AZ31 alloys. The density of each porous material is $0.5 \mathrm{Mg} / \mathrm{m}^{3}$. 
based on microstructure using the criteria of smoothly joined parts because the chip of well-joined parts is remelted and solidified. Figure 3(a) shows that the shape of the AZ91D chips sintered at $575^{\circ} \mathrm{C}$ is round and the joined part appears adequate as mentioned earlier. AM60B alloy is as well-joined as AZ91D alloy, because the shape of its chips is also round and the joined part appears adequate. However, in the case of AZ31 alloy, although the shape of the chip is not like saw teeth, it is sharp and not around. Moreover, the joined part is thin, and it does not look adequate. The difference in the type of joined part obtained with the alloys is likely due to differences in the amounts of compound contained in each alloy and the range of their respective semi-solid temperatures.

Therefore, a cross section of the joined parts of the alloys was analyzed by EPMA. Figure 4 shows the result of quantitative analysis and X-ray images of the joined parts of (a) AZ91D and (b) AZ31 alloys. In AZ91D alloy, a
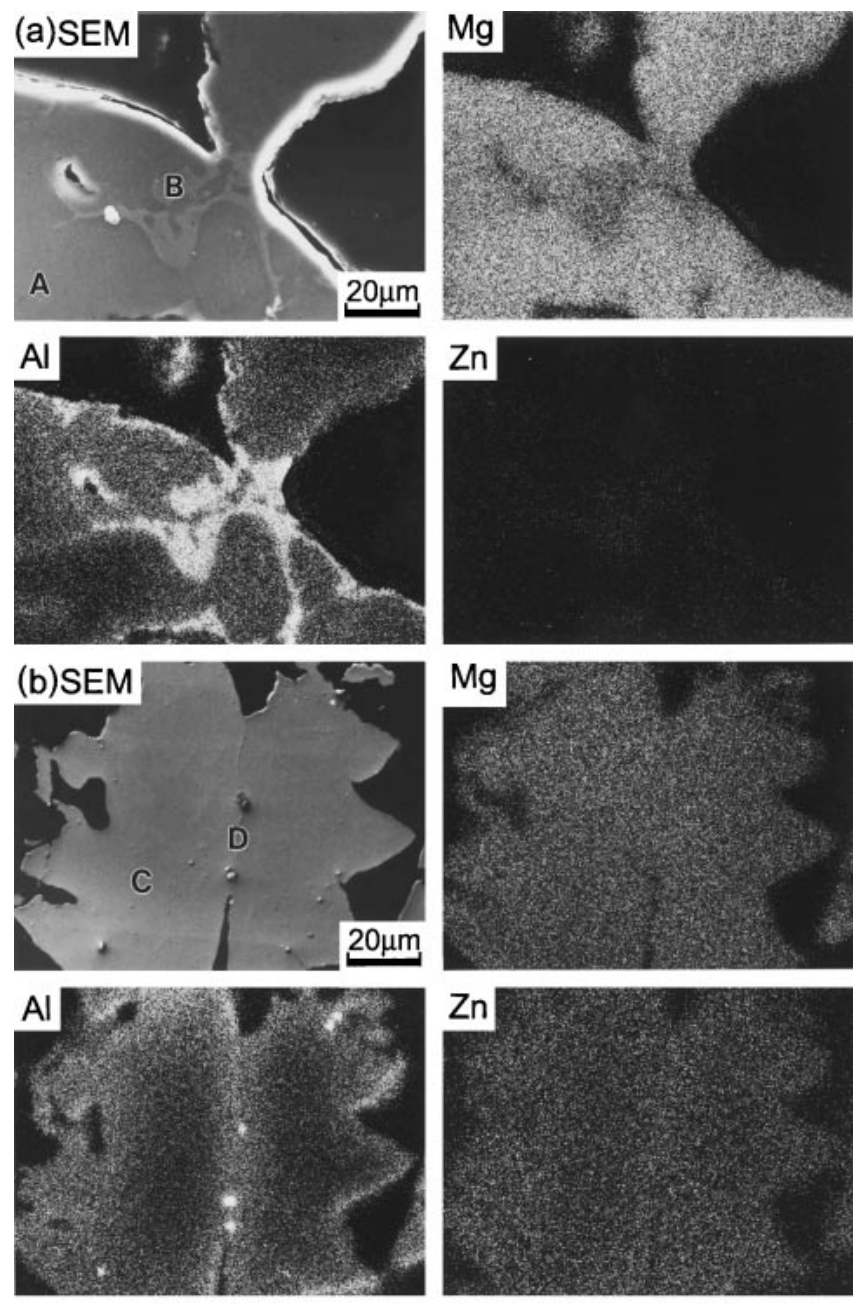

Chemical compositions of each part.(mol\%)

\begin{tabular}{l|cr}
\hline & $\mathrm{Mg}$ & $\mathrm{Al}$ \\
\hline $\mathrm{A}$ & 91.6 & 8.1 \\
$\mathrm{~B}$ & 69.1 & 29.9 \\
\hline $\mathrm{C}$ & 97.9 & 1.9 \\
$\mathrm{D}$ & 95.8 & 3.8 \\
\hline
\end{tabular}

Fig. 4 Results of quantitative analysis and X-ray images of the joined parts of (a) AZ91D and (b) AZ31 alloys. compound of $\mathrm{Mg}-\mathrm{Al}$ system is observed in the joined part. This means that the $\mathrm{Mg}-\mathrm{Al}$ compound crystallizes during solidification of localized joined parts that melt during sintering. In AZ31 alloy, the $\mathrm{Mg}-\mathrm{Al}$ compound does not crystallize but the aluminum content of the joined part is concentrated. Furthermore, the amount of aluminum contained in solid solution becomes large with increasing aluminum content of the alloy. Considering the above results, the difference in the microstructures of the joined parts is caused by the different aluminum contents of the alloys. Nonequilibrium solidified $\mathrm{Mg}-\mathrm{Al}$ compound is melted by rapid heating during PECS, and the solidus line of the equilibrium phase diagram shifts to the left. Therefore, the range of semisolid temperature for non-equilibrium condition is larger than that of equilibrium condition. In the AZ31 alloy, the semisolid range becomes large compared with that of equilibrium condition, but it is narrower than AZ91D and AM60B and AZ31 alloy have no eutectic compound even when nonequilibrium solidification. Therefore, it is difficult to determine the sintering temperature needed to obtain a suitable joined part because the semi-solid temperature range is narrow. During PECS process, the specimen temperature is controlled by measuring the mold temperature and this makes it difficult to control the temperature if the semi-solid temperature range is narrow.

\subsection{Compressive test}

Figure 5 shows the stress-strain curves of porous samples of AZ91D having different pore ratios and that of the bulk material shown for comparison. The compressive behavior of the porous samples is completely different compared to the bulk material. Essentially, there are plateau regions with nearly constant flow stresses in the case of the porous samples. This means that the plateau region absorbs impact energy until the stress rapidly increases. Thus in comparison with the bulk material, the ability of the porous samples to absorb impact energy is remarkably improved. The same

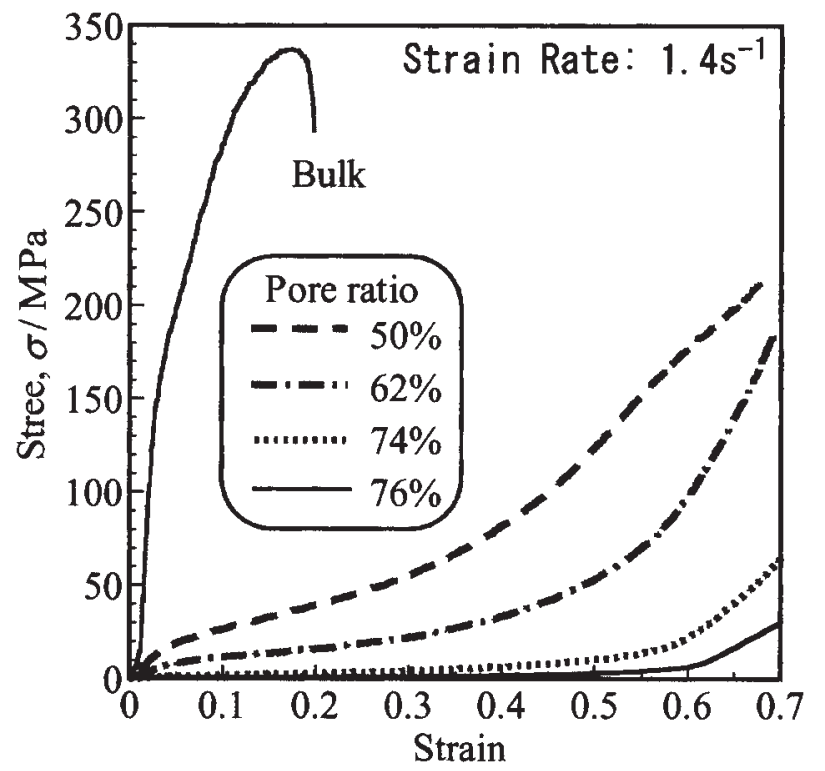

Fig. 5 The stress-strain curves of porous samples of AZ91D alloy having different pore ratios. 

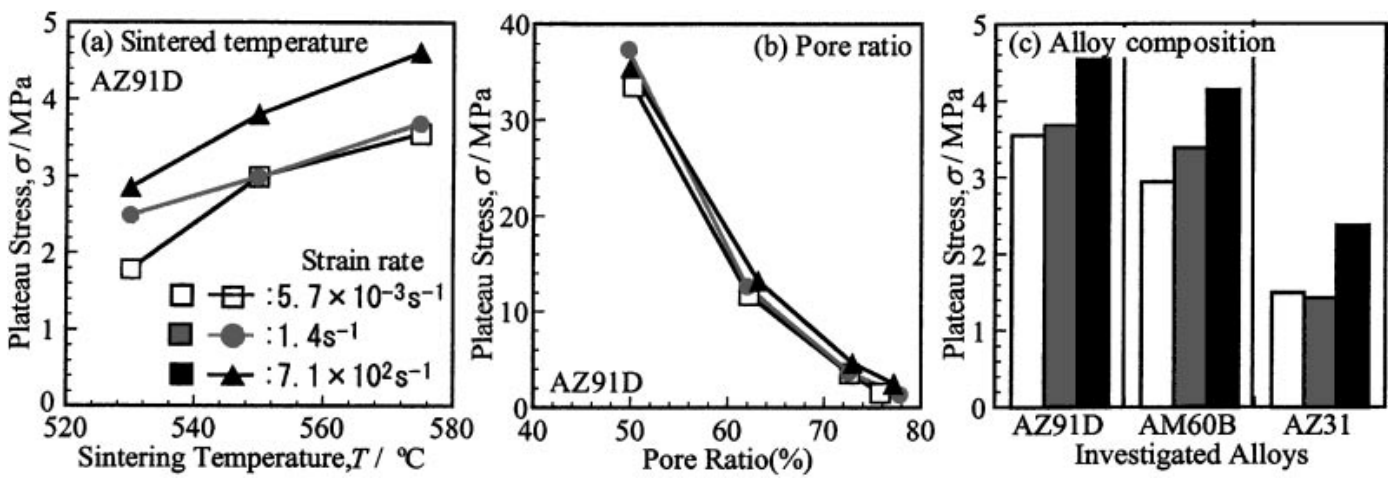

Fig. 6 Effect of (a) sintered temperature, (b) pore ratio and (c) alloy composition on plateau stress.

results were also obtained by Mukai et al. ${ }^{15)}$ The plateau stress increases with decreasing pore ratio. However, the plateau stresses obtained in this study increases as the strain increases because the density is high compared to cell structured materials. Therefore, plateau stresses are taken to be at halfway from the elastic region at the initial stage to the point where the flow stress rapidly increases because of the densification of the specimens.

Figure 6 shows the effects of sintering temperature, pore ratio and alloy composition on plateau stress. As shown in Fig. 6(a), the plateau stress increases with increasing sintering temperature because the joined part becomes rigid. The plateau stress also increases with increasing strain rate. As shown in Fig. 6(b), the plateau stress is about $37.3 \mathrm{MPa}$ when the pore ratio is about $50 \%$, and it is only about $1.4 \mathrm{MPa}$ when the pore ratio is about $78 \%$. Thus, if pore ratio becomes big, the plateau stress rapidly decreases. The joined part of a sample with high pore ratio is more rigid than that of a low pore ratio sample. But, the sample of low pore ratio has a higher plateau stress than the sample of high pore ratio, because it has a lot of chips. The effect of alloy composition on plateau stress is shown in a Fig. 6(c). There is a tendency for the plateau stress to increase with increasing strain rate in all of the alloys. However, the plateau stress of AZ31 alloy is the lowest among the three alloys because of insufficient joined parts. Porous samples of AZ91D and AM60B alloys do not exhibit a big difference in plateau stress because both of the alloys have enough well-joined parts. However, bulk specimen of AZ91D alloy is stronger than that of AM60B alloy, and therefore, the porous materials follow the same trend. Considering the above results, it is clear that pore ratio has the most effect on plateau stress.

Figure 7 shows the relationship between relative stress and relative density obtained for the investigated alloys. GibsonAshby $^{20)}$ analyzed the relationship between the relative stress, $\sigma_{p l} / \sigma_{y s}$, and the relative density, $\rho / \rho_{s}$, assuming that plastic collapse occurs when the moment exerted by the compressive force exceeds the fully plastic moment of the cell edges, where $\sigma_{p l}$ is the plastic-collapse stress, $\sigma_{y s}$ is the yield stress of the cell wall (edge) material, $\rho$ is the density of the cellular material and $\rho_{s}$ is the density of the cell wall (edge) material, respectively. The relationship between the relative stress and the relative density for open-celled material is given by eq. (1),

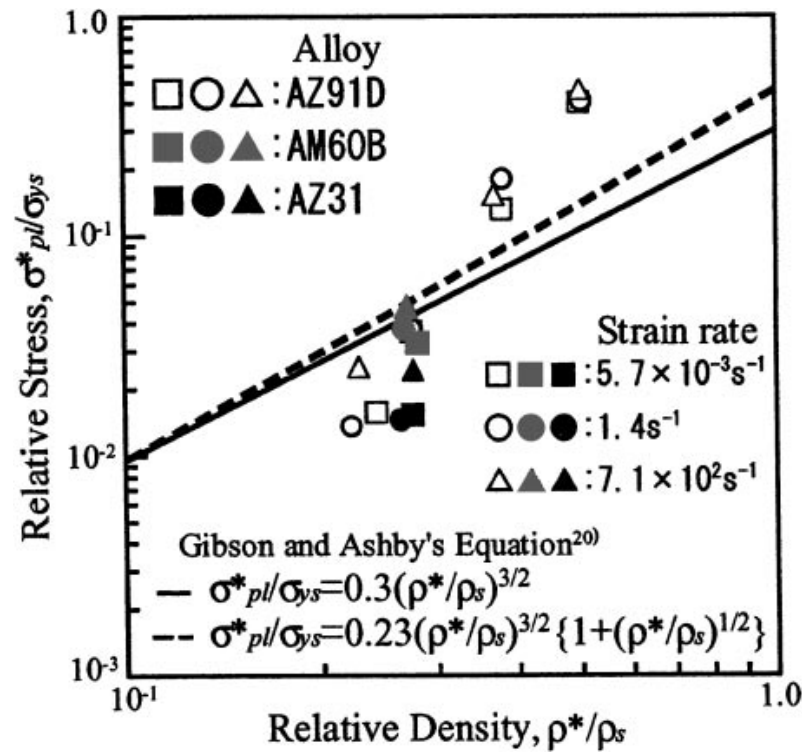

Fig. 7 Relationship between relative stress and relative density of investigated alloys.

$$
\sigma_{p l}^{*} / \sigma_{y s}=C\left(\rho^{*} / \rho_{s}\right)^{3 / 2}
$$

where $C$ is a constant. Refinements are possible but have very little effect on the result. At higher densities, the dimensions of the cell corners must be subtracted from the length of the beam, and corrections must be made to the equation for the density. When this is done the last eq. (2) becomes,

$$
\sigma_{p l}^{*} / \sigma_{y s}=C^{\prime}\left(\rho^{*} / \rho_{s}\right)^{3 / 2}\left\{1+\left(\rho^{*} / \rho_{s}\right)^{1 / 2}\right\}
$$

The experimental value for a porous material of low density is lower than the theoretical value, and experimental value for a porous material of high density is higher than the theoretical value. It is thought that the theoretical equation does not consider the material characteristics and joined part condition. Therefore, it is possible that porous materials are not crushed only by bending stress as implied in the theoretical equation because joined parts of AZ91D and AM60B alloys contain $\mathrm{Mg}-\mathrm{Al}$ compound and the joined part of AZ31 alloy has a high aluminum concentration. The joined parts of AZ31alloy are weak because the joined part is thin, and it does not look adequate. 

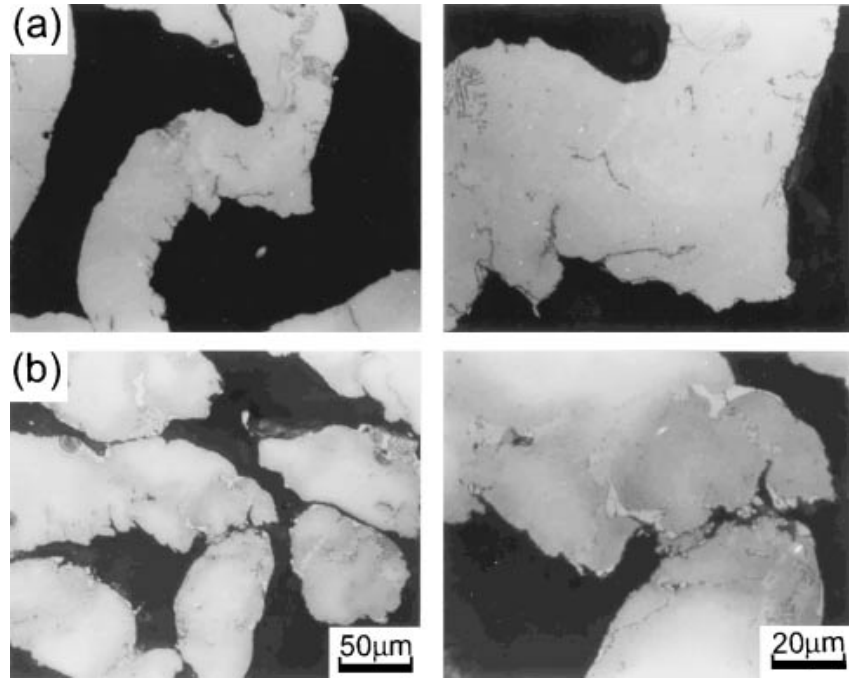

Fig. 8 Microstructure of cross section of (a) 25\% and (b) $50 \%$ compressed porous materials of AZ91D alloy.

Figure 8 shows a cross section microstructure of (a) $25 \%$ and (b) $50 \%$ compressed porous materials of AZ91D alloy. The porous specimens were prepared under the condition of the pore ratio of $74 \%$ and sintering temperature of $575^{\circ} \mathrm{C}$. $\mathrm{Mg}-\mathrm{Al}$ compound crystallizes in joined parts of AZ91D porous materials as shown in Fig. 4(a). In 25\% compressed specimen (Fig. 8(a)), a small amount of $\mathrm{Mg}-\mathrm{Al}$ compound exists in the joined parts, and this makes the cell edges to bend easily during compression. However, the large amount of $\mathrm{Mg}-\mathrm{Al}$ compound that exist in the joined parts of the specimen compressed up to $50 \%$ causes fracture in the joined parts as shown in Fig. 8(b). In the theoretical equation given by Gibson-Ashby, plastic collapse is assumed to occur when the moment exerted on the cell edges exceeds the fully plastic moment creating plastic hinges at corners of the cell. However, the obtained result is different from the theoretical value because fracture occurs at joined parts (corners of the cell) as shown in Fig. 7.

\section{Conclusions}

(1) Porous magnesium alloys can be made by PECS process, and larger semi-solid range with increasing aluminum content result in suitable joined parts.

(2) The compression characteristics show that the variation of the plateau stress is big because of the different state of joined parts by PECS. However, the plateau strain is almost not changed.

(3) The plateau stresses of the porous samples investigated in this study are in the range from 1.3 to $37.3 \mathrm{MPa}$. Pore ratio is the most important factor that affects plateau stress.
(4) The compression characteristics show that if the pore ratio becomes big, the plateau stress is lower and plateau strain is large.

\section{Acknowledgements}

This research is supported by a Grant-in-Aid for Scientific Research on Priority Area(B) "Platform Science and Technology for Advanced Magnesium Alloys" from the Ministry of Education, Culture, Sports Science and Technology of Japan.

\section{REFERENCES}

1) I. A. Anyanwu, S. Kamado and Y. Kojima: Mater. Trans. 42 (2001) 1206-1211.

2) I. A. Anyanwu, S. Kamado and Y. Kojima: Mater. Trans. 42 (2001) 1212-1218.

3) A. A. Luo, M. P. Balogh and B. R. Powell: Metall. Mater. Trans. A 33A (2002) 567-574.

4) Y. Yoshida, H. Yamada, S. Kamado and Y. Kojima: J. JILM 51 (2001) 556-562.

5) Y. Yoshida, L. Cisar, S. Kamado and Y. Kojima: J. JILM 52 (2002) 559-565.

6) T. Mukai, M. Yamanoi, H. Watanabe, K. Ishikawa and K. Higashi: Mater. Trans. 42 (2001) 1177-1181.

7) S. Kamado, I. A. Anyanwu, S. Nozawa, Y. Kojima, S. Takeda and T. Ishida: Proc. Fourth Pacific Rim Int. Conf. Advanced Materials and Processing(PRICM4), ed. by S. Hanada, Z. Zhong, S. W. Nam and R. N. Wright, (The Japan Institute of Metals, 2001) pp. 1175-1178.

8) F. Simancik: Handbook of Cellular Metals, Production, Processing, Applications, ed. by H. P. Degischer and B. Kriszt, (WILEY-VCH, Weinheim 2002) pp. 1-4.

9) H. P. Degischer et al.: Handbook of Cellular Metals, Production, Processing, Applications, ed. by H. P. Degischer and B. Kriszt, (WILEY-VCH, Weinheim 2002) pp. 5-70.

10) T. Ichitsubo, M. Tane, H. Ogi, M. Hirao, T. Ikeda and H. Nakajima: Acta Mater. 50 (2002) 4105-4115.

11) E. Andrews, W. Sanders and L. J. Gibson: Mater. Sci. Eng. A270 (1999) 113-124.

12) O. B. Olurin, N. A. Fleck and M. F. Ashby: Mater. Sci. Eng. A291 (2000) 136-146.

13) I. W. Hall, M. Guden and C.-J. Yu: Scr. Mater. 43 (2000) 515-521.

14) T. Miyoshi, M. Itoh, T. Mukai, H. Kanahashi, H. Kohzu, S. Tanabe and K. Higashi: Scr. Mater. 41 (1999) 1055-1060.

15) T. Mukai, H. Kanahashi, Y. Yamada, K. Shimojima, M. Mabuchi, T. G. Nieh and K. Higashi: Scr. Mater. 41 (1999) 365-371.

16) C. E. Wen, Y. Yamada, K. Shimojima, M. Mabuchi, N. Nakamura and T. Asahina: Mater. Sci. Forum 350-351 (2000) 359-364.

17) K. Shimojima, Y. Chino, Y. Yamada, C. E. Wen and M. Mabuchi: Mater. Trans. 42 (2001) 1326-1331.

18) M. Tokita: J. Soc. Powder Technol. 30 (1993) 790-804.

19) H. Okumura, K. Watanabe, S. Kamado and Y. Kojima: Mater. Sci. Forum 419-422 (2003) 1019-1024.

20) L. J. Gibson and M. F. Ashby: Cellular Solids, Structure and Properties 1st edition, (Pergamon Press, Oxford, 1988) pp. 143-145. 